\title{
WORKPLACE OUTCOMES, THE EXAMPLE OF BULGARIAN CORPORATIONS
}

\author{
Philip Ivanov ${ }^{1, \mathrm{a}, *}$ and Mariana Usheva ${ }^{2, \mathrm{~b}}$ \\ ${ }^{1}$ Department of Management and Marketing, Faculty of Economics, SWU "Neofit Rilski" \\ Blagoevgrad \\ ${ }^{2}$ Department of Management and Marketing, Faculty of Economics, SWU "Neofit Rilski" \\ Blagoevgrad \\ afilip.ivanov.1@abv.bg, ${ }^{\mathrm{b}}$ m.usheva@abv.bg \\ "Corresponding author
}

Cite as: Ivanov, P., Usheva, M. (2021). Workplace outcomes, the example of Bulgarian corporations, Ekonomicko-manazerske spektrum, 15(1), 84-96.

Available at: dx.doi.org/10.26552/ems.2021.1.84-96

Received: 26 February 2021; Received in revised form: 7 May 2021; Accepted: 13 May 2021; Available online: 21 May 2021

\begin{abstract}
The current study is a part of a larger empirical research project aiming to examine the interaction between human motivation and work outcomes. Based on our work on human motivation, we acquired data on the interaction between certain work outcomes, namely: propensity for staying at one's current company; psychological tension; pride in working for one's company; work engagement; work satisfaction; work initiative. The research was conducted in the form of a survey between April 2020 and June 2020. The group of respondents represents workers from various sectors of Bulgarian economy $(n=145)$ and employees of a government-owned railway company $(n=451)$, totaling five hundred and ninety-six participants. The main aim of the survey was to establish the interdependency and interaction between work motivation and outcomes in the workplace. The results examined in the study provide a proof of a strong relationship between psychological tension and three of the examined outcomes. A relationship was found between propensity for staying at one's current company and pride one takes in working there, work satisfaction, work engagement; work initiative, and psychological tension. Furthermore, we managed to prove a significant link between company pride and satisfaction from work; initiative; propensity for staying at one's company. In addition, proof was established of the interaction between engagement and satisfaction, company pride, propensity for staying at one's company, work initiative. A strong relationship was therefore proven between the examined work outcomes for the selected group of respondents. We estimated the statistical significance of our model as well as the correlation between the variables. Consequently, the paper forms a contribution to the science of human resource management.
\end{abstract}

Keywords: work outcomes; work conditions; work motivation

JEL Classification: M12; M52; M54

\section{Introduction}

Work-related outcomes are indisputably the most important aspect of working life. Therefore, every possible interaction and influence upon them matters. In this section, we will examine the views of several authors related to work outcomes. Firstly, we will underline the 
possible influences of other work aspects on potential work outcomes. Various aspects from the environment, such as one's psychological state, emotional traits, motivational dispositions, leadership, etc., could influence work outcomes. We will try to examine these influences to bring more clarity to the topic and to underline the importance of our research.

Feedback can have a strong impact on work outcomes, mostly through interaction of a worker with their environment. Alternatively, as concluded by Belschak and Hartog (2009), positive or negative feedback can greatly influence the emotional state of workers, resulting in a corresponding influence on performance, engagement, turn over intentions, and identification with the organization. Furthermore, Locke and Latham (2005) defined feedback alongside with interesting and intriguing tasks, and self-regulation as the basis of their goal setting theory. Hence, feedback can be seen as one of the most important job characteristics (Oldham and Hackman, 1981; Gillet et al., 2017). Therefore, this aspect of work has a significant impact on work outcomes, mostly through its influence on work motivation. Furthermore, we will examine some examples of influence of workplace motivation on the eventual outcomes. Although the current paper does not focus primarily on motivation, the two variables (work outcomes and motivation) are highly dependent upon one another. Hence, we must examine the theories of motivation, which will contribute to validity of our research.

Motivation is a complex aspect of the human psychology and has a great influence on an individual's behavior. It can be defined as a resource-allocation process where time and energy are allocated to an array of tasks (Latham and Pinder, 2005). Therefore, motivation is the process of the directing the behavior of individuals in a given direction, with a certain persistency and energy of execution. Some scholars define motivation as a set of everactualizing needs, which can be hardly fulfilled to their maximum. Such examples are the work of Maslow (1954), who defined five groups of needs - psychological needs, safety needs, love and belonging needs, esteem needs, and self-actualization needs. He formulated their hierarchy in his famous pyramid and the main prerequisite for moving higher up the pyramid of basic human needs is subjectively sufficient fulfilment of the needs on its preceding lower levels. This was defined as the satisfaction-progression process. There are many more postulates formulated by Maslow, which made his theory one of the most popular in work motivation, but we will not further examine it. Another theory with a significant influence on work motivation research is that of Alderfer. Building on the work of Maslow, he aimed to contribute to the latter's theory and to formulate a more concrete and practically applicable theory of human motivation. Alderfer (1969) defined three groups of needs - existence, relatedness and growth. His most important contribution was the formulation of the frustration-regression principle, which can be explained as the tendency of people to prioritize their more concrete needs at the expense of the less concrete ones. Alderfer proposed a process wherein people can revert to a certain level of needs if these are perceived as more concrete at the moment. Other examples of formulation of needs as a part of human motivation include the works of Hogan and Waremfelts (2003) who described biological needs, needs for acceptance and approval, status, power and control over resources, predictability, and order. These authors therefore view individuals as creatures in state of permanent need which can be hardly ever satisfied fully. Among other authors with significant contributions to theories of need are Herzberg and MacClelland. Herzberg (1968) acknowledged two factors influencing human motivation: motivators and hygiene factors, whereas the latter contribute only in the sense of inspiring dissatisfaction with work due to their absence. The only true motivational influence on people was then seen as coming from the motivators. From another perspective, MacCleland (1986) acknowledged the urge for achievement as the most important aspect of the process of human motivation. 
Although the theories mentioned above are very important for human resource management, they cannot be fully accepted in a practical environment. As we stated above, motivation is a very complexed process, which can be influenced by various aspects of the environment.

Theories based on the view that motivation is an outcome of interaction between humans and their environment, are called "process" theories of human motivation. Authors who adhere to this standpoint do not define motivation as propensity for need satisfaction but rather as a complex interaction between an individual and their environment. We will examine some of the works on process theories of motivation, some examples of which include the expectancy theory, in which expected results and outcomes motivate the chosen behavior, as defined by Lawler and Porter (1967); the goal-setting theory, whose authors define interesting and challenging tasks as the main prerequisite for high motivation, alongside high performance, and subsequent feedback, cf. Locke and Latham (2002); Latham and Pinder (2005); and the job characteristics model, where the characteristics of the job play a vital role in motivation of the workers, cf. Oldham and Hackman (1981).

There are numerous other views on human motivation, but our main goal was to describe it as the main factor influencing work outcomes. Consequently, any factors influencing motivation can indirectly influence work outcomes. We can therefore state that factors such as personality traits (Bipp, 2010); autonomy support (Gellet et al., 2017); leadership (Keating et al., 2013); leadership empowerment (Zang, Barton, 2010); age and lifespan (Kanfer and Ackerman, 2004), social interaction, and cultural dependencies (Wood and Bandura, 1989; Bandura, 2002; Roe et al., 2000; O'Neill and Davis, 2011), could have significant impact on work outcomes. Many of the aforementioned factors, alongside the motivational theories examined, can therefore be expected to influence work outcomes, mostly because human motivation is strongly connected to many of the outcomes examined in the present paper. Later in this section, we will examine some direct interactions of the numerous aspects of the working life and their outcomes in the workplace.

Psychosocial safety can contribute to greater job involvement and commitment of time and energy in work of the organization. In turn, greater involvement and effort are positively related to superior performance (Brown and Leigh, 1996; Zhang and Bartol, 2010). Hence, psychological climate can be very important in the workplace, mostly by influencing the propensity of the workers to engage more effort in their work. We partly confirm this statement with our results. Some authors relate other psychological aspects to work performance. Rosander and Blomberg (2021) conducted a study examining the probability of being bullied at work, based on one's origin. The authors found out that the chance of being bullied at work is greater when you come from a country different than your colleagues. They described a greater correlation with larger difference in both cultural and geographical aspect between the country one is working in and originating from. One's origin can therefore be the reason behind high psychological strain at work.

Psychological state is even more important in the current age of the COVID-19 pandemic. People have come under greater psychological stress, some have lost their employment, which undisputedly increased their psychological tension. The role of HR managers is therefore likewise becoming more important, in terms of management of the psychological environment in the workplace. As stated by Collings et al. (2021), HR leaders are uniquely placed to navigate the paradox emerging from the COVID-19 pandemic and this has placed them front and center in organizational responses to the crisis, and how they perform is likely to impact organizational sustainability and lives of workers (p. 11). The pandemic has significantly changed the circumstances and the role of HR managers has become broader. Most importantly, leaders must do what they can to protect psychological integrity of the workers, as this will guarantee 
better overall results of the company. There is empirical proof of the aforementioned tendencies. Coun et al. (2021) found significant correlations between psychological empowerment in the workplace and workplace proactivity, workplace flexibility, professional autonomy, access to knowledge, and empowering leadership. This highlights the importance of HR managers in formation of proactive and autonomous professionals, which could have the potential to improve the overall results in almost every sector.

As for another aspect, Gellatly (1996) examined conscientiousness as a factor influencing performance expectancy and goal choice, concluding that people with higher levels of conscientiousness show better performance, with another psychologically related dependency with values and human behavior. Alternatively, as stated by Latham and Pinder (2005), values influence behavior, as normative standards used to determine and choose alternative, socially acceptable forms of behavior (p. 488). Therefore, values can influence the chosen behavior in the workplace, resulting in a corresponding influence on work-related outcomes.

An interesting contribution by Wood (2021) managed to prove various kinds of influence, originating in the environment, with significant influence on work performance and work involvement. The author underlined the importance of outcomes and the mediators influencing them in the field, examining papers from the past thirty years. Similar approach was taken by Beijer et al. (2021), who reviewed numerous papers, concluding the importance of examining work-related outcomes along with the factors influencing them, from the employee standpoint. We completely agree with this, mostly because of the great importance of people in every workplace. This was the main reason we chose to focus on employees in our study, even though some scholars suggest a group approach to study of human resources (Herzberg, 1968; Boon et al., 2019), which is indeed in some cases a completely reliable approach. We nevertheless believe individualistic approach to be better suited to our research.

Effects of mismatched demands at work can contribute to negative work outcomes. Shaufeli et al. (2009) found that when job demands (overwork, emotional pressure, and work-home interference) increase but job resources (control at work, feedback, social support, and learning) decrease, future negative outcomes in the form of "burnout" also increase (p.908). There is therefore proof of a positive correlation of the mismatch in motivation of workers and negative work outcomes. In our opinion, burnout would decrease many of the positive outcomes in the workplace. In line with our research, psychological tension as a part of the burnout effect, had a highly negative effect upon the rest of the outcomes we examined. For example, Ahola (2007) linked burnout with increase in depressive and anxiety disorders, as well as alcohol dependence (p. 75-78). In addition, Taris et al. (2003) conducted a study among eighty-one organizations, aiming to examine the dependencies of interaction between reduction in job stress and negative psychological states. The authors proved a positive relationship between the implementation of measures for reducing job stress and the actual psychological states at work. Consequently, the management of the company is the main mediator in influencing psychological state of workers in the form of burnout at work. In addition, Bakker and de Vries (2020) state that when employees experience job strain, they show avoidance coping and self-undermining, resulting in more job demands and more job strain (p. 15). Hence, psychological tension can be the main reason for lower levels of performance, engagement, and self-regulation at work. Moreover, Salmela-Aro and Upadyaya (2018) proved a strong relationship between lifespan and burnout dependencies. The authors found that caregiving demands were related to work burnout particularly during late career, whereas economic demands were related to burnout during early career (p. 195). Consequently, career stage can have a strong effect on one's psychological state, resulting in turn in the corresponding effect on work outcomes. Although we have not examined such effects in our study, we agree with these findings. Current stage of one's life 
can have a severe effect on many work outcomes, mostly due to the different demands based on the respective social and work life characteristics.

Generally, psychological tension can be expected to have negatively impact on work behavior. Beehr et al (2000) as cited by O'Neil and Davis (2011) state that customer service employees reporting chronic stress exhibit particularly poor job performance. Hence, stress in the workplace can affect performance. Therefore, we can expect it to have strong influence on other work-related outcomes, too. From another perspective, psychological strain is dependent on the motivational outcomes, i.e., when people are not optimally motivated, they tend to increase their psychological tension due to higher job demands and lower job resources in the form of direct payment or other motivators. Hence, motivation can be accepted as the main mediator of outcomes. This should be examined in a different study, since our goal in the present paper is to find dependencies between work-related outcomes.

As we showed in the first section of our paper, work outcomes are of significant interest to scholars. In our opinion, this is due mostly to their high practical importance. We live in an age of fierce competition in almost every sector of the economy. Often, competitive advantages are coming from inside the company, i.e., the employees. Therefore, it is of upmost importance for the companies to take care and to contribute to wellbeing of their workers. This could provide better overall results, as was confirmed by numerous authors over the years.

\section{Methodology}

As examined above, work outcomes could impact the overall results of companies. Hence, the influences upon them, as well as the interaction and the interdependencies between the examined outcomes are crucial for understanding and explaining work results. In the present paper we examine: propensity for staying in the company (PSW); psychological tension among employees (PSYTENS); pride in working for the current company (PRIDE); engagement (ENGAGE); work satisfaction (SATISF); work initiative (INIT). Each of the outcomes is evaluated by first asking the respondents questions and inviting them to assess each using a scale. The respective questions for each outcome are as follows:

- Propensity for staying in the company: If it were up to you, would you work at your current company five years from now?

- Psychological tension: Do you feel that you are working in a psychologically tense environment?

- Pride in working for the company: Do you feel proud to work for your current company?

- Engagement: To what degree do you feel engaged with the work and overall results of your company?

- Satisfaction: Please evaluate your overall satisfaction from work.

- Initiative: Please express your readiness for engaging in tasks and your overall initiative.

We examined the variables using a five-point Likert scale in the form of ratings from one to five, or with progressively scaled responses. Respondents were asked to evaluate each statement; based on their assessments we were able to identify interesting interactions and dependencies between the examined work-related outcomes. The results were gathered using an online-based survey platform, which helped us facilitate a more effective distribution and analysis of the data. We divided the respondents into two groups. In the first group, the respondents were part of different organizations from various regions of Bulgaria. The second group was formed by employees of Bulgaria's biggest railway company, with branches in six Bulgarian cities and operating in the whole territory of the country. 
The larger part of the first group were women (69\%). The largest part of the respondents was between thirty-six and forty-five years old (31.7\%), $29.7 \%$ were between twenty-six and thirtyfive years old, $26.9 \%$ were older than forty-five years, and the smallest age group were those aged between eighteen and twenty-five years $(11.7 \%)$. The larger part of the respondents finished higher education ( $24.5 \%$ with a bachelor's and $45.5 \%$ with a master's degree), leaving only $27.6 \%$ of people with secondary education, with the rest of the respondents with education either lower than high school or higher than a master's degree. The first group therefore consisted mostly of women in active age, with higher education. The number of respondents in this group was $n=145$.

The railway employee group had the following demographics: men and women were relatively equally represented with women at $52.5 \%$ and men at $47.5 \%$. The largest part was those older than forty-five (53\%), followed by the group between thirty-six and forty-five years $(32.2 \%)$, while younger respondents aged between twenty-six and thirty-five years represented $13.2 \%$, and those between eighteen and twenty-five years only $1.6 \%$. The largest part of the respondents had a master's degree $(83 \%)$, followed by bachelor's degree $(11.4 \%)$, while a relatively small group had education lower than high school or higher than a master's degree. The second group therefore consisted mostly of middle-aged men and women with higher education.

For testing the results, we used regression analysis. We examined the interdependencies between all the examined variables, meaning that we examined the regression between all the outcomes, i.e., we examined one variable first as an independent and then as a dependent variable. By doing so, we were able to establish the statistical significance and correlation between our outcomes. Our hypotheses were formulated as follows:

Hypothesis 1: There is a significant influence of psychological tension, work pride, engagement, overall satisfaction, and initiative on propensity for staying with one's current company.

Hypothesis 2: Pride is affected by propensity for staying with one's current company, work engagement, satisfaction, psychological tension, and work initiative.

Hypothesis 3: Satisfaction is affected by psychological tension, propensity for staying, engagement, pride, and initiative.

Hypothesis 4: Engagement is significantly affected by work satisfaction, propensity for staying, psychological tension, and initiative.

Hypothesis 5: Initiative is influenced by engagement, satisfaction, pride, propensity for staying, and psychological tension.

Hypothesis 6: Psychological tension is affected by initiative, satisfaction, engagement, pride, and propensity for staying.

Hypothesis 7: The relationship between job satisfaction and propensity for staying with one's current company is relatively strong.

Hypothesis 8: Initiative has a relatively strong relationship with engagement, satisfaction, and pride.

Hypothesis 9: Engagement has a relatively strong positive relationship with work satisfaction, pride, propensity for staying, and initiative.

Hypothesis 10: Propensity for staying with one's current company is strongly positively correlated with engagement, pride, initiative, and work satisfaction.

Hypothesis 11: There is a strong negative effect of psychological tension on all the other variables. 
For testing the hypotheses, we conducted regression with a dependent variable for each of the examined outcomes. We also conducted a correlational analysis, using the MS Excel software for both. By doing so, we managed to respectively prove or reject our formulated hypotheses.

\section{Results}

We examined the descriptive statistics for each variable in Table 1: mean, median, mode, standard deviation, standard error, and sample variance, as well as the measures of normality, kurtosis, and skewness.

Table 1: Descriptive statistics

\begin{tabular}{|c|c|c|c|c|c|c|c|c|c|c|c|}
\hline PSW & & $\begin{array}{l}\text { PSYTEN } \\
\text { S } \\
\end{array}$ & & PRIDE & & $\begin{array}{l}\text { ENGAG } \\
\text { E }\end{array}$ & & SATISF & & INIT & \\
\hline Mean & $\begin{array}{l}3.6 \\
37\end{array}$ & Mean & $\begin{array}{l}3.1 \\
17\end{array}$ & Mean & $\begin{array}{l}3.6 \\
47\end{array}$ & Mean & $\begin{array}{l}3.8 \\
87\end{array}$ & Mean & $\begin{array}{l}3.75 \\
2\end{array}$ & Mean & $\begin{array}{l}3.8 \\
34\end{array}$ \\
\hline Standard & 0.0 & Standard & 0.0 & Standard & 0.0 & Standard & 0.0 & Standard & 0.03 & Standard & 0.0 \\
\hline Error & 40 & Error & 44 & Error & 37 & Error & 37 & Error & 5 & Error & 38 \\
\hline Median & 4 & Median & 3 & Median & 4 & Median & 4 & Median & 4 & Median & 4 \\
\hline Mode & 4 & Mode & 2 & Mode & 4 & Mode & 4 & Mode & 4 & Mode & 4 \\
\hline Standard & 0.9 & Standard & 1.0 & Standard & 0.9 & Standard & 0.8 & Standard & 0.86 & Standard & 0.9 \\
\hline Dev. & 72 & Dev. & 72 & Dev. & 00 & Dev. & 95 & Dev. & 3 & Dev. & 23 \\
\hline Sample & 0.9 & Sample & 1.1 & Sample & 0.8 & Sample & 0.8 & Sample & 0.74 & Sample & 0.8 \\
\hline Var. & 46 & Var. & 49 & Var. & 11 & Var. & 01 & Var. & 5 & Var. & 52 \\
\hline Kurtosis & $\begin{array}{l}0.0 \\
70\end{array}$ & Kurtosis & $\begin{array}{l}0.8 \\
65\end{array}$ & Kurtosis & $\begin{array}{l}0.0 \\
45\end{array}$ & Kurtosis & $\begin{array}{l}1.6 \\
04\end{array}$ & Kurtosis & $\begin{array}{l}0.04 \\
7\end{array}$ & Kurtosis & $\begin{array}{l}0.5 \\
54\end{array}$ \\
\hline Skewness & $\begin{array}{l}0.5 \\
16\end{array}$ & Skewness & $\begin{array}{l}0.0 \\
81\end{array}$ & Skewness & $\begin{array}{l}0.5 \\
01\end{array}$ & Skewness & $\begin{array}{l}0.9 \\
13\end{array}$ & Skewness & $\begin{array}{l}- \\
0.33 \\
7\end{array}$ & Skewness & $\begin{array}{l}0.7 \\
01\end{array}$ \\
\hline
\end{tabular}

Source: Authors

We can observe leptokurtic normality with propensity for staying, meaning there are higher values for this outcome than for the sample average. The same observation is valid for psychological tension, pride, engagement, and initiative. We can observe platykurtic results for the satisfaction outcome, meaning there are lower-than-the-average results for this variable. The skewness results confirm the normality test of the results.

We examined and calculated the Cronbach $\alpha=0.62$, meaning that we can accept the results of the analysis of our survey, as suggested by George and Mallerey (2003), and our model is acceptably reliable. Consequently, we proceeded to our regression analysis.

For more clarity, we examined each outcome individually with respect to a variable dependent on the rest of the outcomes. First, we conducted a regression analysis of the dependent variable of the propensity for staying with one's current company. With respect to significance of the regression model for our dependent variable (propensity for staying), we found $\mathrm{P}$ values close to zero $(\mathrm{P}<0.01$ and $\mathrm{P}<0.05)$ for all independent variables. Hence, the model was found to be statistically significant. For more clarity, we provide the results with respect to the dependent variable in the form of a table.

We chose to leave the scientific notation for significance, simply because once converted, the values are equal to zero. As we can see in Table 2, the significance levels are below the suggested 0.05 . We can also see the regression statistics, based on which we can conclude a strong relationship between the independent and dependent variables. We can also see a 
statistically significant interaction between all the outcomes, which were treated as independent variables in this model.

Table 2: Overall significance of the dependent variable PSW; regression statistics and P-values for the different outcomes

\begin{tabular}{lllll}
\hline Significance F & Regression Statistics & & OUTCOMES & P-value \\
\hline $6.0974 \mathrm{E}-101$ & Multiple R & 0.75 & PSYTENS & 0.00099 \\
& R Square & 0.56 & PRIDE & $3.375 \mathrm{E}-37$ \\
& Adjusted R Square & 0.55 & ENGAGE & 0.0369111 \\
& Standard Error & 0.65 & SATISF & $5.542 \mathrm{E}-07$ \\
& Observations & 596 & INIT & 0.0008303 \\
\hline
\end{tabular}

Source: Authors

When treating psychological tension as a dependent variable, we could not prove a statistically significant influence of work pride or initiative $(\mathrm{P}>0.05)$. We were able to observe a significant influence of propensity for staying, work engagement, and satisfaction $(\mathrm{P}<0.001)$. We again summarize the results in table, as shown below:

Table 3: Overall significance of the dependent variable PSYCTENS; regression statistics and P-values for the different outcomes

\begin{tabular}{lllll}
\hline Significance $\mathbf{F}$ & Regression Statistics & & OUTCOMES & P-value \\
\hline $6.0974 \mathrm{E}-101$ & Multiple R & 0.38 & PSW & 0.000990016 \\
& R Square & 0.14 & PRIDE & 0.209731436 \\
& Adjusted R Square & 0.13 & ENGAGE & $6.67347 \mathrm{E}-05$ \\
& Standard Error & 1.00 & SATISF & $6.28939 \mathrm{E}-05$ \\
& Observations & 596 & INIT & 0.720793443 \\
\hline
\end{tabular}

Source: Authors

Pride manifested a statically significant dependency on most of the outcomes. Again, for more clarity, we provide the significances and regressive statistics in Table 4.

In our examination of the dependent variable pride, we were able to prove significant influence of the independent variables as examined in Table 4. The overall significance of the model was high as well, with a $\mathrm{P}$ value close to zero. $\mathrm{R}$ squared is again high at 0.52 , meaning that $52 \%$ of the changes in pride are due to changes in the other outcomes. The correlation between the independent and the dependent variable is also relatively strong. Consequently, the model can be accepted as statistically significant.

Table 4: Overall significance of dependent variable PRIDE; regression statistics and P-values for the different outcomes

\begin{tabular}{lllll}
\hline Significance F & Regression Statistics & & OUTCOMES & P-value \\
\hline $3.51537 \mathrm{E}-19$ & Multiple R & 0.72 & PSYTENS & 0.209731436 \\
& R Square & 0.52 & PSW & $3.3753 \mathrm{E}-37$ \\
& Adjusted R Square & 0.52 & ENGAGE & 0.133588007 \\
& Standard Error & 0.62 & SATISF & 0.001870451 \\
& Observations & 596 & INIT & $9.01756 \mathrm{E}-05$ \\
\hline
\end{tabular}

Source: Authors 
We chose the same line of analysis for engagement. Our results regarding its significance is shown in Table 5.

Table 5: Overall significance of dependent variable ENGAGE; regression statistics and P-values for the different outcomes

\begin{tabular}{lllll}
\hline Significance F & Regression Statistics & & OUTCOMES & P-value \\
\hline $7.57484 \mathrm{E}-92$ & Multiple R & 0.39 & PRIDE & $5.44031 \mathrm{E}-12$ \\
& R Square & 0.15 & PSYTENS & 0.133588007 \\
& Adjusted R Square & 0.14 & PSW & $6.67347 \mathrm{E}-05$ \\
& Standard Error & 0.83 & SATISF & 0.036911141 \\
& Observations & 596 & INIT & $4.24975 \mathrm{E}-05$ \\
\hline
\end{tabular}

Source: Authors

As we can see in Table 5, the significance level was again high. We could not prove a significant influence of psychological tension on engagement, but we can see a statistically significant influence of the rest of the examined outcomes. Surprisingly, R squared is relatively low, which could mean that the current model is not well formulated.

Work satisfaction was again strongly correlated with the rest of the outcomes. Again, we show the results in Table 6:

Table 6: Overall significance of dependent variable SATISF; regression statistics and P-values for the different outcomes

\begin{tabular}{lllll}
\hline Significance $\mathbf{F}$ & Regression Statistics & & OUTCOMES & P-value \\
\hline $2.49102 \mathrm{E}-90$ & Multiple R & 0.72 & ENGAGE & $4.24975 \mathrm{E}-05$ \\
& R Square & 0.52 & PRIDE & 0.001870451 \\
& Adjusted R Square & 0.51 & PSYTENS & $6.28939 \mathrm{E}-05$ \\
& Standard Error & 0.60 & PSW & $5.54214 \mathrm{E}-07$ \\
& Observations & 596 & INIT & $1.78957 \mathrm{E}-25$ \\
\hline
\end{tabular}

Source: Authors

As we can see in Table 6, the significance levels were again high and the correlation between the independent and dependent variable was strong. $\mathrm{R}$ squared was relatively high, hence we can accept the model as statistically significant.

We show the last model, for the work initiative outcome, in Table 7.

Table 7: Overall significance of dependent variable INIT; regression statistics and P-values for the different outcomes

\begin{tabular}{lllll}
\hline Significance $\mathbf{F}$ & Regression Statistics & & OUTCOMES & P-value \\
\hline $5.86314 \mathrm{E}-75$ & Multiple R & 0.67 & SATISF & $1.78957 \mathrm{E}-25$ \\
& R Square & 0.46 & ENGAGE & 0.234018651 \\
& Adjusted R Square & 0.45 & PRIDE & $9.01756 \mathrm{E}-05$ \\
& Standard Error & 0.68 & PSYTENS & 0.720793443 \\
& Observations & 596 & PSW & 0.000830311 \\
\hline
\end{tabular}

Source: Authors

As we can see, we could not prove any statistical significance between initiative and engagement, or for psychological tension, but were able to observe a high significance level for 
the other three outcomes. Regression was again relatively strong, and R squared was once again high.

Next, we examined the correlation between all the variables analyzed above. By doing so, we were able to observe the overall influence of the outcomes on one another, and arrive at the respective conclusions.

Table 8: Correlational analysis between the outcomes

\begin{tabular}{|c|c|c|c|c|c|c|}
\hline & INIT & SATISF & ENGAGE & PRIDE & PSYTENS & PSW \\
\hline INIT & 1 & & & & & \\
\hline SATISF & $0.63 * * * * *$ & 1 & & & & \\
\hline ENGAGE & 0.27 & $0.33 * * * * *$ & 1 & & & \\
\hline PRIDE & $0.52 * * * * *$ & $0.55^{* *}$ & 0.28 & 1 & & \\
\hline PSYTENS & -0.21 & $-0.30 * * * * *$ & $0.02 * * * * *$ & -0.26 & 1 & \\
\hline PSW & $0.53 * * *$ & $0.58 * * * * *$ & $0.29 *$ & $0.69 * * * * *$ & $-0.31 * * * * *$ & 1 \\
\hline
\end{tabular}

Notes: $* p<0.05 ; * * p<0.01 ; * * * p<0.001 ; * * * * p<0.0001 ; * * * * * p<0.00001$

Source: Authors

Table 8 shows the correlations between the examined variables, and the related probability, providing an easier way to analyze the data. As mentioned above, some probability values were very close to zero, and we therefore opted to examine them to the fifth decimal place. As shown in the table, there are numerous tendencies, which we can observe based on our analysis. We will discuss the results in more detail below.

\section{Discussion}

Work related outcomes are potentially crucial when formulating the overall results of a company. Many researchers have examined the influence of numerous factors on some of these work outcomes. Although there is a strong interest in the topic, we could not find any research papers focused on analyzing the interdependencies among the outcomes themselves. As we examined above, motivation can be the strongest influencer on work attitudes and outcomes in a practical environment. Hence, our research was in fact a part of a greater research project focused on motivation. The formulation of our scientific goal led us to examine the interaction between the outcomes. This section of the article discusses the results and tests our hypotheses.

In our results section, we examined the significance and probability of our models, and individually analyzed every outcome as a dependent variable. This helped us to confirm or reject our first six hypotheses. Based on our results, we can fully prove our first hypothesis. As shown in Table 2, the probability of regression between all other outcomes was less than 0.05 , in some cases close to zero. Consequently, propensity for staying with one's current company could be significantly influenced by the other examined work-related outcomes.

When it comes to our second hypothesis, we can partly confirm a significant influence on pride by the rest of the outcomes. We observed high probabilities when examining propensity for staying, work satisfaction, and initiative, although probability levels for psychological tension and engagement were low. Hence, this hypothesis was partly confirmed, only for certain variables, as detailed above.

The third hypothesis was fully proved and therefore accepted. The probability levels when examining satisfaction as a dependent variable were relatively high. When examined for all outcomes, in most cases, as shown in Table 6, the probability levels were close to zero. 
We partly confirmed our fourth hypothesis. In Table 5, we examined the results of the regression analysis with engagement as a dependent variable. As we can see in the table, the probability was high when examining pride, propensity for staying, work satisfaction, and initiative. Hence, we can accept the hypothesis almost fully.

Initiative had a significant correlation with three of our examined independent variables in the form of the outcomes. Table 7 shows the results related to our fifth hypothesis. As we can see, there is proof that leads us to partially accept the hypothesis, because of the relatively strong probability levels for initiative and some of the remaining outcomes.

Psychological tension showed a significant relationship with propensity for staying, work engagement, and satisfaction. We could not prove any significance when examining the relationship with pride and initiative. Consequently, our sixth hypothesis can be partially accepted.

For the rest of the hypotheses, we will formulate a correlational model, based on the results in Table 8. This will help us examine the actual correlation between the variables more easily.

In Figure 1, we propose our model for the interactions and interdependencies among the examined outcomes. We can therefore proceed to evaluate the rest of our hypotheses. The relationship between job satisfaction and propensity for staying is relatively strong. As we examined in our probability testing, there was a statistically significant relationship between the two variables. As we can see in the model above, the correlational coefficient is 0.58 . Consequently, the relationship between these two variables is relatively strong. Hence, we can completely confirm our seventh hypothesis.

We can observe a relatively strong relationship between initiative, satisfaction, and pride. Although we could not prove a significant relationship between initiative and engagement, we can partly confirm our eighth hypothesis. As we can see in the model, shown in Figure 1, correlation coefficients for initiative with satisfaction and pride, are, respectively, 0.63 and 0.52 , hence, we observe a strong relationship between both initiative and satisfaction and initiative and pride.

Our ninth hypothesis was partly rejected by the results. As shown in our probability testing, there was low statistical significance in most of the outcomes with respect to engagement. In addition, where there was statistical significance, the correlation was weak or moderate.

Hence, we could not prove a strong positive relationship between engagement and the rest of the outcomes.

Propensity for staying showed a good correlation probability for all the remaining outcomes. Consequently, every variable examined here can be accepted as a factor influencing the inclination of people to stay or leave their company. When it comes to the strength of these influences, we can conclude that job satisfaction $(0.58)$, pride $(0.69)$ and initiative $(0.53)$ have the strongest relationship with propensity for staying. We also observed a positive relationship with engagement (0.29). Hence, we can accept our tenth hypothesis.

The negative relationship hypothesized for psychological tension was partially confirmed. We examined statistical significance for three of the outcomes examined, and for every of them, psychological tension had either weak or negative effect. As we can see from Figure 1, psychological tension has a moderately negative relationship with work satisfaction (-0.30) and propensity for staying (-0.31). Consequently, we can partially accept our last hypothesis, mostly with respect to the discovered negative correlations. 
Figure 1: Correlation model with statistically significant variables

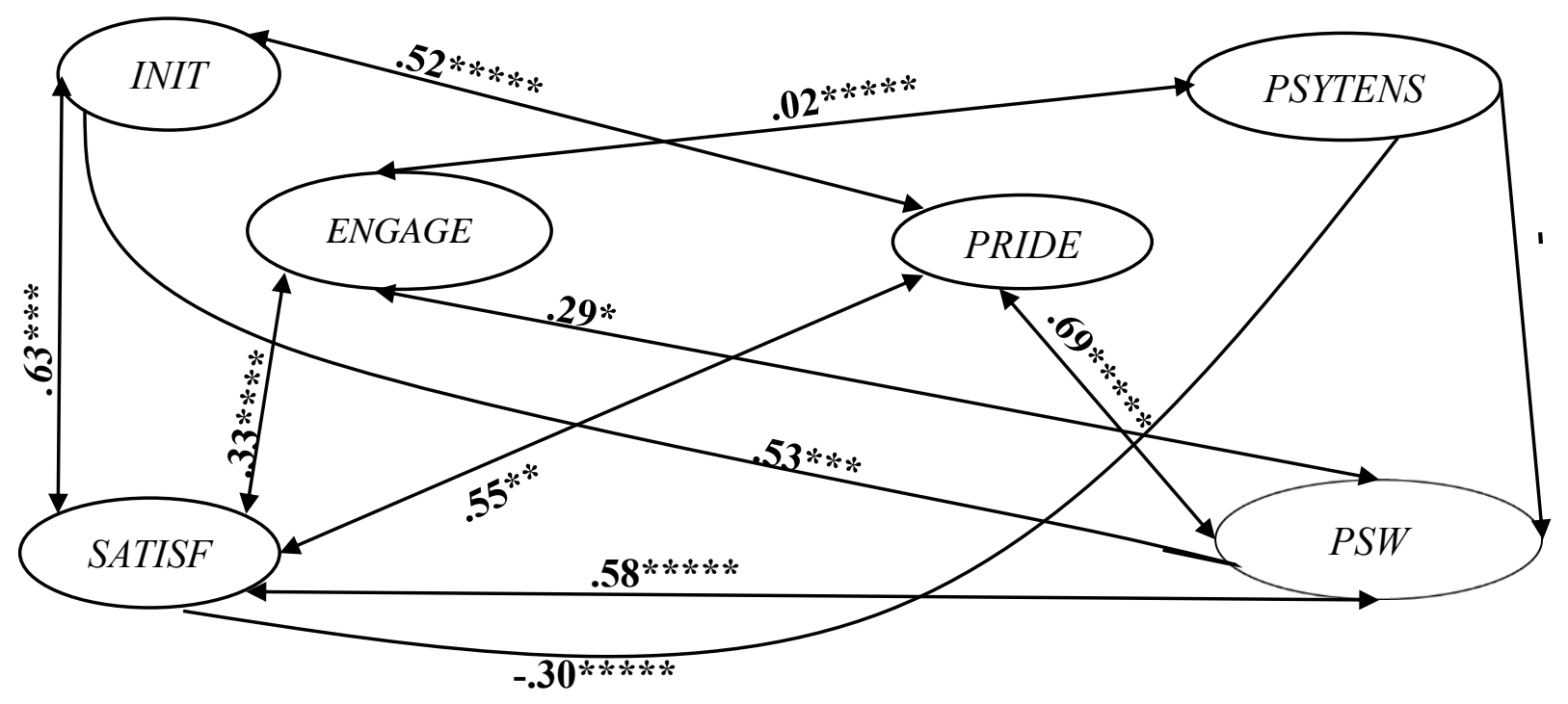

Note: $* p<0.05 ; * * p<0.01 ; * * * p<0.001 ; * * * * p<0.0001 ; * * * * * p<0.00001$

Source: Authors

\section{Conclusion}

We confirmed there was indeed a relationship between most of the variables examined. There was a strong positive correlation between initiative and work satisfaction; initiative and pride; initiative and the propensity for staying with one's company. Consequently, this outcome is important mostly with respect to increasing work satisfaction, pride, and helping people to want to stay with the company. We found a firmly positive relationship between work satisfaction and engagement; work satisfaction and pride; work satisfaction and propensity for staying. A firmly moderate negative correlation was found between work satisfaction and psychological tension at work. Consequently, work satisfaction in work was found to be highly dependent on all the remaining outcomes examined. We managed to prove a significant correlation between work engagement and propensity for staying with one's company-the more engaged workers are with their job, the more likely they are to stay with the company.

A significant and strong positive relationship was found between propensity for staying and work pride, i.e., as work pride increases, people are more likely to stay with the company. Psychological tension was found to be a negative influence on the outcomes, with a significant correlation. As the tension grows, propensity for staying with one's company and work satisfaction both decrease.

\section{References}

Ahola, K. (2007). Occupational burnout and health. Finnish Institute Occupational Health. https://helda.helsinki.fi/handle/10138/19788.

Alderfer, C. (1969). An empirical test of a new theory of human needs. Organizational Behavior \& Human Performance, 4(2), 142-175

Bakker, A., \& de Vries, J. (2020). Job Demands-Resources theory and self regulation: New explanations and remedies for job burnout. Anxiety, Stress \& Coping 34(1), 1-21.

Bandura, A. (2002). Social cognitive theory in cultural context. Applied Psychology: An International Review, 51 (2), 269-290.

Beijer, S., Peccei, R., van Heldhoven, M., \& Paauwe, J., (2021). The turn to employees in the measurment of proposed way forward. Human Resource Management Journal, 31(1), 1-17. 
Belschak, F., \& Den Hartog, D. (2009). Consequences of positive and negative feedback: The impact on emotions and extra-role behaviors. Applied Psychology: An International Review, 58(2), 274-303.

Bipp, T. (2010). What people want from their jobs? The big five, core self-evaluations and work motivation. International Journal of Selection and Assessment, 18, 28-39.

Boon, C., Den Hartog, D., \& Lepak, D. (2029). A systematic review of human resource management systems and their mesurment. Journal of Management, 45(6).

Brown, P., \& Leigh, T. (1996). A new look at the psychological climate and its relationship to job involvement, effort and performance. Journal of Applied Psychology, 81(4), 358-368.

Collings, D., Nyberg, A., Wright, P., \& McMackin, J. (2021). Leading through paradox in a COVID-19 world: Human resources comes of age. Human Resources Management Journal, 31(1).

Coun, M., Peters, P., Blomme, R., \& Schaveling, J. (2021). To empower or not to empower, that's the question. Using empowerment process approach to explain employees' workplace proactivity. The International Journal of Human Resource Management.

Gellatly, I. (1996), Conscientiousness and task performance: Test of a cognitive process model. Journal of Applied Psychology, 81(5), 474-482

George, D., \& Mallery, P. (2003). SPSS for Windows step by step: A simple guide and reference. 11.0 update (4th ed.). Boston: Allyn \& Bacon

Gillet, N., Fouquereau, E., Vallerand, R., Abraham, J., \& Colombat, P. (2017). The role of workers' motivational profiles in affective and organizational factors. Journal of Happiness Studies, 19, 1151-1174.

Hercberg, F. (1968). One more time: How do we motivate employees? Harvard Business Review - JanuaryFebruary, 53-62.

Hogan, R., \& Warremfeltz, R. (2003). Educating the modern manager. Academy of Management Journal, 46(2), 74-84.

Kanfer, R., \& Ackerman, P. (2004). Adult develop, and work motivation. The Academy of Management Review, 29(3), 440-458.

Keating, R., Harper, S., \& David, G. (2013). Emotional intelligence dilutes the toxins. Industrial Engineer, 68(3), 66-74.

Latham, G., \& Pinder, C. (2005). Work motivation theory and research at the dawn of the twenty-first century. Annual Psychology Review, 56, 485-516.

Locke, E., \& Latham, G. (2002). Building a practically useful theory of goal setting and task motivation: A $35-$ year odyssey. American Psychologist, 57, 705-717.

Lower, E., \& Porter, L. (1967). The effect of performance on job satisfaction. Industrial Relations, 7(1), 20-28.

MacClelland, D. (1968). The urge to achieve, in Matteson, Ivanevich, Management Classics, BPI, Plano, Texas.

Maslow, A. (1954). Motivation and personality. Harper \& Row publishers, London.

O’Neill, J., \& Davis, K. (2011). Work stress and well-being in hotel industry. International Journal of Hospitality Management, 30, 385-390.

Oldham, G., \& Hackman, J. (1981). Relationships between organizationa structure and employee reactions: Comparing alternative frameworks. Administrative science quarterly, 26(1), 66-83.

Roe, R., Zinovieva, I., Dienes, E., Laurens, A., \& Horn, T. (2000). A comparison of work motivation in Bulgaria, Hungary and the Netherlands: Test of a model. Applied Psychology: An International Review, 49, 658-687.

Rosander, M., \& Blomberg, S. (2021). Workplace bullying of immigrants working in Sweden. The International Journal of Human Resource Management, 32.

Salmela-Aro, K., \& Upadyaya, K. (2018). Role of demands-resources in work engagement and burnout in different career stages. Journal of Vocational Behavior, 108, 190-200.

Shaufeli, W., Bakker, A., \& Van Rhenen, W. (2009). How changes in job demands and resources predict burnout, work engagement, and sickness absenteeism. Journal of Organizational Behavior, 30(7), 893-917.

Taris, T. W., Kompier, M. A. J., Geurts, S. A. E., Schreurs, P. J. G., Schaufeli, W. B., de Boer, E., Sepmeijer, K. J., \& Wattez, C. (2003). Stress management interventions in the Dutch domiciliary care sector: Findings from 81 organizations. International Journal of Stress Management, 10(4), 297-325.

Wood, R., \& Bandura, A. (1989). Social cognitive theory of organizational management. Academy of Management Review, 14(3), 361-384.

Wood, S. (2021). Developments in the HRM-Performance research stream: The mediation studies. German Journal of Human Resource Management, 35(1), 83-113.

Zhang, X., \& Bartol, K. (2010). Linking empowering leadership and employee creativity: The influence of psychological empowerment, intrinsic motivation, and creative process engagement. The Academy of Management Review, 53(1), 107-128. 